\title{
Características de frutos de pimentão pulverizados com produtos de ação bactericida
}

\author{
Mariella C Rocha $^{1 *}$; Margarida Goréte F do Carmo ${ }^{1 * *}$; José Carlos Polidoro ${ }^{3}$; Débora AG da Silva ${ }^{1 *}$; \\ Maria do Carmo A Fernandes ${ }^{2}$ \\ ${ }^{1}$ UFRRJ, Dep ${ }^{\text {to }}$ Fitotecnia; ${ }^{2}$ PESAGRO-RIO, Br 465, Km 47 da antiga Rodovia Rio-São Paulo, 23.851-970 Seropédica-RJ; E-mail: \\ marigonnis@ig.com.br; gorete@ufrrj.br; ${ }^{3}$ Embrapa-Solos, Jardim Botânico, RJ. *Alunos de Pós Graduação em Fitotecnia, Bolsistas \\ CAPES; **Bolsista CNPq
}

\begin{abstract}
RESUMO
Muitas das tecnologias desenvolvidas para a cultura do pimentão estão voltadas para a melhoria da produtividade e da aparência dos frutos sem considerar aspectos como sabor, valor nutricional e resíduos tóxicos remanescentes. O presente trabalho teve como objetivos avaliar o efeito de pulverizações semanais com biofertilizante Agrobio $(5 \%)$, oxicloreto de cobre $\left(2,4 \mathrm{~g} \mathrm{~L}^{-1}\right)$, sulfato de estreptomicina + oxitetraciclina $\left(0,8 \mathrm{~g} \mathrm{~L}^{-1}\right)$ e testemunha (água), sobre a produtividade e a qualidade de frutos de três cultivares de pimentão: Magda, Cascadura Itaipu e o híbrido Magali R. Adotou-se o delineamento de blocos ao acaso com quatro repetições, em esquema fatorial (4x3). As variáveis analisadas foram produtividade, características físicas e físico-químicas, teor e acúmulo de fósforo, cobre e chumbo nos frutos. Observou-se maior diâmetro longitudinal e volume dos frutos e maiores produtividade e eficiência no aproveitamento do fósforo pelo híbrido 'Magali R'. Observaram-se diferenças entre as cultivares quanto à taxa de acúmulo de cobre nos frutos, tendo sido quatro vezes maior em frutos de "Magda" pulverizados com oxicloreto de cobre que nos demais tratamentos e, nenhum efeito dos tratamentos sobre o acúmulo de chumbo. Os teores de cobre e chumbo encontrados, porém, estão dentro da faixa aceitável pela Anvisa. Constatou-se, ainda, que as aplicações de cobre afetam o sabor dos frutos, principalmente por influenciar em sua acidez total titulável, expressa em maiores teores de ácido cítrico e menores valores de $\mathrm{pH}$. Os resultados apontam, ainda, para uma relação entre acúmulo de cobre nos frutos e eficiência do uso de fósforo, sendo, porém, necessários novos estudos para sua comprovação.
\end{abstract}

Palavras-chave: Capsicum annuum L., biofertilizante, oxicloreto de cobre, sulfato de estreptomicina, oxitetraciclina, pós-colheita.

\section{ABSTRACT \\ Characteristics of bell pepper fruits affected by products with bactericidal action}

Most technologies used for bell pepper production emphasize yields, shape and size of the fruits, with less attention to features such as flavor, nutritional value and toxic residue content. The objectives of the present work, accomplished in field and laboratory conditions, were to evaluate the effect of weekly sprayings of Agrobio biofertilizer (5\%v.v.), copper oxychloride ( $2.4 \mathrm{~g}$ active ingredient $\mathrm{L}$ $\left.{ }^{1}\right)$, streptomycin sulphate + oxitetracycline $(0.8 \%$ active ingredient $\mathrm{L}^{-1}$ ) and water as control treatment, on the production and quality of fruits of three cultivars of bell peppers: "Magda", "Cascadura Itaipu" and "Magali R". In both conditions, a randomized complete block design with four replicates was used, in a factorial scheme (4x3). The analyzed variables were productivity, physical and physicalchemical features, percentage and total $\mathrm{P}, \mathrm{Cu}$ and $\mathrm{Pb}$ in fruits. Larger longitudinal diameter and volume as well as higher productivity and efficiency of P use by 'Magali R' were found. There was no effect of the treatments on $\mathrm{Pb}$ accumulation but effects were found on $\mathrm{Cu}$. Higher $\mathrm{Cu}$ concentrations were found in fruits treated with copper oxychloride, especially in cultivar ' Magda', although concentrations found were within the range acceptable by the national sanitary agency (ANVISA) parameters. Besides, $\mathrm{Cu}$ applications afffected fruit flavor, primarily by changing total titrable acidity and lower $\mathrm{pH}$. Results also suggested a relationship of $\mathrm{Cu}$ content and $\mathrm{P}$ efficiency use by pepper plants, which need further confirmation.

Keywords: Capsicum annuи L, biofertilizer, copper oxychloride, streptomycin sulphate, oxitetracycline, postharvest.

\section{(Recebido para publicação em 12 de julho de 2005; aceito em 26 de abril de 2006)}

\begin{abstract}
A cultura do pimentão (Capsicum annuит L.) apresenta elevado valor comercial e está entre as dez hortaliças mais consumidas no Brasil. Seus frutos são comercializados, principalmente, na coloração verde e vermelha, apesar de serem também produzidos frutos de cor amarela, marfim, laranja e arroxeada (Filgueira, 2003).

A qualidade de frutos de hortaliças é caracterizada com base em atributos como aparência, sabor, textura e valor nutritivo (Chitarra, 1998). Esta caracterização é importante, determinando as
\end{abstract}

variáveis que devem ser observadas para a melhoria da comercialização no mercado interno e externo, bem como para o desenvolvimento de técnicas de armazenamento e de manejo pós-colheita. Assim, torna-se de fundamental importância a avaliação do efeito de práticas de manejo sobre a produtividade, a qualidade química e física do produto e a longevidade durante o processo de comercialização.

Entre as práticas de manejo freqüentemente utilizadas em cultivos de pimentão estão as pulverizações com fungicidas à base de cobre, seja para o controle de doenças fúngicas ou bacterianas, e de antibióticos para o controle das fitobacterioses (Carmo et al., 2001). O uso freqüente de fungicidas cúpricos pode contribuir para a contaminação do ambiente com cobre e outros metais pesados (Santos et al, 2002) e para o desenvolvimento de sintomas de fitotoxidez (Aguiar, 1997), e para o acúmulo destes nos frutos. Estes produtos, porém, podem ser fontes deste micronutriente. $\mathrm{O}$ pimentão alcança a máxima produtividade quando os teo- 
res de $\mathrm{Fe}, \mathrm{Mn}, \mathrm{Zn}$ e $\mathrm{Cu}$ no tecido foliar variam entre 569 e 610, 293 e 321, 101 e 107 e 64 e $70 \mathrm{mg} \mathrm{kg}^{-1}$, respectivamente (Gusmán \& Romero, 1988). As concentrações de cobre em alimentos estão, em geral, na faixa de 0,2 a $44 \mathrm{mg} \mathrm{kg}^{-1}$ de matéria seca sendo, porém, na maioria dos alimentos inferior a $10 \mathrm{mg} \mathrm{kg}^{-1}$ (Pedroso \& Lima, 2001). Segundo a Portaria n 33 da Agência Nacional de Vigilância Sanitária, que dispõe sobre os parâmetros para a Ingestão Diária Recomendada (IDR) de vitaminas, minerais, proteínas e outros nutrientes para os indivíduos e diferentes grupos populacionais, um adulto pode consumir uma dose diária de três miligramas de cobre (ANVISA, 1998).

O emprego de antibióticos no controle de fitobacterioses, por sua vez, também pode ser problemático. Existem apenas dois princípios ativos registrados para este fim, o sulfato de estreptomicina e a oxitetraciclina (McManus et al, 2002) e o seu emprego em fitobacteriologia pode envolver problemas técnicos pela fácil e freqüente seleção de estirpes resistentes na população do patógeno, pela escassez de estudos sobre a sua persistência em órgãos vegetais utilizados para o consumo humano, além de afetarem o equilíbrio dos agroecossistemas e apresentarem custo elevado (McManus et al., 2002).

Entre as alternativas que vem sendo testadas no manejo de doenças de plantas estão os biofertilizantes, aos quais são atribuídas propriedades nutricionais, fungistáticas, inseticidas, e bacteriostáticas, quando aplicados via foliar (Tratch \& Bettiol, 1997; Fernandes, 2000; Deleito et al., 2005). Em sua composição microbiológica já foram constatados um número grande de bactérias, leveduras e bacilos (Deleito, 2005). Um dos biofertilizantes que vem sendo utilizado em várias culturas tem sido o Agrobio, produzido e pesquisado na Estação Experimental de Seropédica (EES) da Pesagro-Rio. O Agrobio é obtido em sistema aberto pela ação de diferentes microrganismos (Deleito, 2005) em substrato composto pela mistura de água, esterco bovino, melaço, leite e macro e micronutrientes. Após cerca de 56 dias, dependendo das condições de ambiente, o produto está pronto para ser utilizado (Fernandes, 2000).
Em sua composição química são encontrados, 34,69 $\mathrm{g} \mathrm{L}^{-1}$ de matéria orgânica, $0,8 \%$ de carbono, $631 \mathrm{mg} \mathrm{L}^{-1}$ de nitrogênio, $170 \mathrm{mg} \mathrm{L}^{-1}$ de fósforo, $1,2 \mathrm{~g} \mathrm{~L}^{-1}$ de potássio, $1,59 \mathrm{~g} \mathrm{~L}^{-1}$ de cálcio e 480 $\mathrm{mg} \mathrm{L}^{-1}$ de magnésio, além de traços de outros micronutrientes essenciais às plantas (Fernandes, 2000).

Apesar do uso frequiente de produtos à base de cobre e de antibióticos e do uso crescente de biofertilizantes em pulverizações da cultura do pimentão, na literatura científica não são encontrados trabalhos que avaliam seus efeitos sobre a qualidade dos frutos. Desta forma, o presente trabalho foi feito com o objetivo de avaliar o efeito de cultivar e de pulverizações com oxicloreto de cobre, sulfato de estreptomicina + oxitetraciclina e biofertilizante Agrobio sobre a produtividade, a qualidade física e físico-química de frutos de pimentão e teor e acúmulo de fósforo, cobre e chumbo nos mesmos.

\section{MATERIAL E MÉTODOS}

Este trabalho foi realizado, em condições de campo, na UFRRJ em Seropédica, RJ, de março a dezembro de 2002.

A área experimental foi dividida em 48 parcelas de $11,5 \mathrm{~m}^{2}$, contendo cada uma 24 plantas, distribuídas em três fileiras de oito plantas. Como parcela útil, consideraram-se apenas as seis plantas localizadas na fileira central, espaçadas em 1,2 x 0,40 m. Foram comparados quatro tratamentos: oxicloreto de cobre $\left(2,4 \mathrm{~g} \mathrm{~L} \mathrm{~L}^{-1}\right.$ de ia); sulfato de estreptomicina + oxitetraciclina $(0,8 \mathrm{~g}$ $\mathrm{L}^{-1}$ de ia); biofertilizante Agrobio (5\%) e testemunha (água) e três cultivares de pimentão Magda, Cascadura Itaipu e o híbrido Magali R, em arranjo fatorial $4 \times 3$. Adotou-se o delineamento de blocos ao acaso com quatro repetições.

A adubação mineral, realizada seguindo a análise do solo e as recomendações de adubação para o estado do Rio de Janeiro (De Polli et al., 1998), foi feita com a aplicação de $16.200 \mathrm{~kg} \mathrm{ha}^{-1}$ de esterco bovino, além de $400 \mathrm{~kg} \mathrm{ha}^{-1}$ de superfosfato simples e $93 \mathrm{~kg} \mathrm{ha}^{-1} \mathrm{de}$ cloreto de potássio aplicados no sulco de plantio. Aos 30 dias após o transplantio das mudas, foi feita a apli- cação do equivalente a $60 \mathrm{~kg} \mathrm{ha}^{-1} \mathrm{de}$ uréia e de $60 \mathrm{~kg} \mathrm{ha}^{-1}$ de cloreto de potássio.

Após o transplante das mudas, seguiu-se o manejo usual da cultura, com capinas, adição de cobertura com palha seca de grama e condução das plantas em estacas individuais. A partir do florescimento, iniciaram-se as adubações de cobertura, efetuadas a cada 21 dias, quando se aplicaram sulfato de amônio $\left(60 \mathrm{~kg} \mathrm{ha}^{-1}\right)$ e cloreto de potássio $\left(15 \mathrm{~kg} \mathrm{ha}^{-1}\right)$. As irrigações, por aspersão, foram efetuadas a cada três a cinco dias conforme a necessidade da cultura. Para o controle da broca dos frutos, foram feitas duas pulverizações com inseticida à base de deltametrina (250 g $\left.\mathrm{L}^{-1}\right)$. Os frutos, colhidos semanalmente, foram levados para o laboratório para seleção, classificação e coleta de amostras para a realização das análises físico-químicas. Foram determinadas a massa média e a produção de frutos com padrão comercial ao longo de nove colheitas. A produtividade final foi estimada por meio do somatório de todas as colheitas e expressa em toneladas por hectare $\left(\mathrm{t} \mathrm{ha}^{-1}\right)$.

As avaliações físicas e físico-químicas dos frutos, ao longo das nove colheitas, incluíram as seguintes determinações: a) diâmetro dos frutos, medido com auxilio de um paquímetro; b) volume, calculado conforme Beltrão et al. (1988); c) coloração, avaliada segundo recomendação de Bussel \& Kenigsberger (1975) onde: 1 frutos totalmente verdes, 2 frutos verdes com traços vermelhos; 3 frutos vermelhos com traços verdes; e 4 frutos totalmente vermelhos; d) textura, determinada com auxílio de um penetrômetro marca Mc-Cormick, modelo FT 011, com ponta de 7,94 mm de diâmetro; e) teor de sólidos solúveis totais (SST), determinado utilizando refratômetro de campo (manual) ATAGO N-1; f) acidez total titulável (ATT), determinada por meio de titulação com $\mathrm{NaOH}(0,1 \mathrm{~N})$; g) pH, determinado com auxílio de um potenciômetro; e h) teores e conteúdos de fósforo, cobre e chumbo (Tedesco et al., 1995). O teor de SST, a ATT e o pH foram determinados de acordo com as normas do Instituto Adolfo Lutz (1976).

Para determinação da textura dos frutos efetuaram-se três leituras na re- 
gião equatorial do fruto, após a remoção da casca. Os resultados foram expressos em libras $\mathrm{cm}^{-2}$. Os resultados da acidez total titulável (ATT) foram expressos em $\%$ de ácido cítrico. Com base no teor de sólidos solúveis (SST) e de acidez total titulável (ATT), calcularam-se os valores da relação SST/ATT. Os teores de fósforo, expressos em $\mathrm{g} \mathrm{Kg}^{-1}$, e os teores de Cobre e chumbo, expressos em $\mathrm{mg} \mathrm{Kg}$ ${ }^{1}$, foram utilizados para estimar a exportação dos mesmos nos frutos de pimentão nos diferentes tratamentos.

Para a determinação dos teores de fósforo, cobre e chumbo nos frutos, o material vegetal foi seco em estufa com ventilação forçada a $75^{\circ} \mathrm{C}$, moído e submetido à digestão sulfúrica para o elemento fósforo e digestão nitro-perclórica para os elementos cobre e chumbo. Neste extrato foram determinados os teores de fósforo, Cobre e chumbo pelo método de Tedesco et al., (1995).

Na análise estatística dos dados de SST, ATT, SST/ATT, pH e textura foram considerados dois grupos distintos, frutos verdes (colorações 1 e 2) e frutos maduros (colorações 3 e 4). Os dados foram submetidos ao teste de normalidade (Lilliefors) e homogeneidade das variâncias (Cochran) e à análise de variância para testar o efeito dos fatores cultivar e produto pulverizado, bem como da interação destes sobre as diferentes variáveis avaliadas, com o uso do teste F-Fisher. As médias foram comparadas pelo teste de Tukey a 5\%. Os teores e conteúdos de Cobre e de fósforo foram, ainda, submetidos à análise de correlação de Pearson, tendo-se considerado os coeficientes maiores que 0,60 e significativos a $5 \%$ pelo teste $t$ - Student. Todos os procedimentos estatísticos foram realizados com o uso do software SAEG v. 8.02 da Universidade Federal de Viçosa, (Ribeiro Jr, 2001).

\section{RESULTADOS E DISCUSSÃO}

Observou-se efeito apenas do fator cultivar sobre a produtividade e sobre as características físicas dos frutos. O híbrido Magali R apresentou maior produtividade de frutos com padrão comercial, número e massa média de frutos que as cultivares 'Magda' e 'Cascadura Itaipu', que não diferiram entre si (Tabela 1). A maior produtividade do hí-

Tabela 1. Efeito de cultivar sobre o número de frutos de pimentão (frutos $\mathrm{m}^{-2}$ ), massa média dos frutos $(\mathrm{g})$, produtividade $\left(\mathrm{t} \mathrm{ha}^{-1}\right)$, diâmetro longitudinal e equatorial $(\mathrm{cm})$, volume $\left(\mathrm{cm}^{3}\right)$ e textura $\left(\mathrm{lb} \mathrm{cm}^{-2}\right)$ dos frutos. Seropédica, UFRRJ, 2002.

\begin{tabular}{|c|c|c|c|c|c|c|}
\hline \multirow{2}{*}{ Cultivar } & \multirow{2}{*}{$\begin{array}{l}\text { Número } \\
\text { de frutos } \\
\left(\mathrm{m}^{2}\right)\end{array}$} & \multirow{2}{*}{$\begin{array}{l}\text { Massa } \\
\text { média do } \\
\text { fruto }(\mathrm{g})\end{array}$} & \multirow{2}{*}{$\begin{array}{c}\text { Produtivi- } \\
\text { dade } \\
\text { (t ha-1) }\end{array}$} & \multicolumn{2}{|c|}{ Diâmetro do fruto $(\mathrm{cm})$} & \multirow{2}{*}{$\begin{array}{c}\text { Volume } \\
\left(\mathrm{cm}^{3}\right)\end{array}$} \\
\hline & & & & Longitudinal & Equatorial & \\
\hline Magda & $5,20 \quad b$ & $84,13 b$ & $4,48 \mathrm{~b}$ & $11,07 \mathrm{~b}$ & $5,59 a$ & $179,33 \mathrm{~b}$ \\
\hline Magali R & 10,93 a & $107,36 \mathrm{a}$ & $11,59 \mathrm{a}$ & $13,44 \mathrm{a}$ & 5,49 a & $213,78 a$ \\
\hline Cascadura Itaipu & $7,54 \quad b$ & $78,70 \mathrm{~b}$ & $6,04 \mathrm{~b}$ & $10,53 \mathrm{c}$ & $5,64 a$ & $181,59 \mathrm{~b}$ \\
\hline
\end{tabular}

"Médias seguidas pela mesma letra não diferem estatisticamente pelo teste de Tukey $5 \%$.

Tabela 2. Efeito de cultivar e produto pulverizado sobre o teor de sólidos solúveis totais (SST), acidez total titulável (ATT), relação entre os sólidos solúveis totais e acidez total titulável (SST/ATT) e pH de frutos de pimentão maduros. Seropédica, UFRRJ, 2002.

\begin{tabular}{lrrrr}
\hline & \multicolumn{4}{c}{ Frutos maduros } \\
\cline { 2 - 5 } Produto & SST ( ${ }^{\circ}$ Brix) & $\begin{array}{c}\text { ATT (\% de } \\
\text { ácido } \\
\text { cítrico) }\end{array}$ & SST/ATT & pH \\
\hline Agrobio & $5,82 \mathrm{a}$ & $1,34 \mathrm{~b}$ & $4,92 \mathrm{a}$ & $5,73 \mathrm{ab}$ \\
Estreptomicina+oxitetretraciclina & $5,86 \mathrm{a}$ & $1,37 \mathrm{~b}$ & $5,13 \mathrm{a}$ & $5,82 \mathrm{a}$ \\
Oxicloreto de Cobre & $6,19 \mathrm{a}$ & $2,10 \mathrm{a}$ & $2,96 \mathrm{a}$ & $5,37 \mathrm{~b}$ \\
Água & $5,67 \mathrm{a}$ & $0,95 \mathrm{~b}$ & $6,66 \mathrm{a}$ & $5,84 \mathrm{a}$ \\
\hline CV\% & 12,60 & 33,55 & 37,63 & 3,19 \\
\hline Cultivar & & & & \\
Magda & $5,95 \mathrm{a}$ & $1,48 \mathrm{a}$ & $4,26 \mathrm{~b}$ & $5,72 \mathrm{a}$ \\
Magali R & $5,94 \mathrm{a}$ & $0,86 \mathrm{~b}$ & $7,39 \mathrm{a}$ & $5,84 \mathrm{a}$ \\
Cascadura Itaipu & $5,59 \mathrm{a}$ & $1,57 \mathrm{a}$ & $4,30 \mathrm{~b}$ & $5,73 \mathrm{a}$ \\
\hline CV\% & 12,14 & 32,59 & 30,54 & 3,85 \\
\hline
\end{tabular}

Médias seguidas pela mesma letra minúscula na coluna não diferem significativamente pelo teste de Tukey a 5\%

brido pode ser explicada pela regularidade da produção ao longo das colheitas, contrapondo-se às oscilações observadas nas duas demais cultivares ao longo do ciclo da cultura. Entretanto, a produtividade foi baixa, mesmo para 'Magali R' (11,6 t.ha-1), uma vez que, são relatadas para o híbrido, em condições de campo, produtividades de 13 a $20 \mathrm{t} \mathrm{ha}^{-1}$ (Ribeiro et al., 2000). Atribuise esse resultado ao fato de terem sido computados os dados de apenas nove semanas de colheita e ao ataque severo da broca pequena dos frutos (Neulocinoides elegantalis) que desclassificou muitos frutos para a comercialização.

Os produtos pulverizados não afetaram a produtividade nem as características físicas dos frutos. Os frutos de 'Magali R' apresentaram significativamente maior diâmetro longitudinal e volume médio que os das duas demais cultivares (Tabela 1), superiores inclu- sive aos valores observados por Singh \& Srivastava (1998) e Ribeiro et al. (2000). Quanto ao diâmetro equatorial dos frutos, não foram observadas diferenças entre as cultivares (Tabela1).

Não foi observado efeito de cultivar nem de produto sobre a textura dos frutos verdes ou maduros. A textura média dos frutos verdes variou de 4,03 a $5,25 \mathrm{lb} \mathrm{cm}^{-2} \mathrm{e}$ a dos frutos maduros de 4,42 a $5,18 \mathrm{lb} \mathrm{cm}^{-2}$, ambos dentro da faixa registrada por Nannetti (2001) para frutos de pimentão recém colhidos $(4,46$ a $7,56 \mathrm{lb} \mathrm{cm}^{-2}$ ).

$\mathrm{O}$ efeito dos tratamentos sobre a composição dos frutos somente foi observado com a maturação dos mesmos, ou seja nos frutos maduros (coloração 3 e 4) (Tabela 2). Entre os frutos verdes, o teor de sólidos solúveis totais (SST) oscilou entre 6,01 e 7,00 ${ }^{\circ}$ Brix, a acidez total titulável (ATT) entre 0,81 e 1,87\% de ácido cítrico e a relação SST/ATT entre 4,65 e 7,76. O pH dos frutos ver- 
Tabela 3. Efeito da interação cultivar e produto pulverizado sobre o teor de fósforo $\left(\mathrm{g} \mathrm{kg}^{-1}\right.$ de massa seca) e de cobre ( $\mathrm{mg} \mathrm{kg}^{-1}$ de massa seca) em frutos de pimentão. Seropédica, UFRRJ, 2002.

\begin{tabular}{|c|c|c|c|c|c|c|}
\hline \multirow{2}{*}{ Produto } & \multicolumn{3}{|c|}{$\begin{array}{c}\text { Teor de fósforo }\left(\mathrm{g} \mathrm{kg}^{-1}\right) \mathrm{de} \\
\text { massa seca }\end{array}$} & \multicolumn{3}{|c|}{$\begin{array}{c}\text { Teor de cobre }\left(\mathrm{mg} \mathrm{kg}^{-1}\right) \mathrm{de} \\
\text { massa seca }\end{array}$} \\
\hline & Magda & Magali $\mathbf{R}$ & $\begin{array}{l}\text { Cascadura } \\
\text { Itaipu }\end{array}$ & Magda & Magali R & $\begin{array}{l}\text { Cascadura } \\
\text { Itaipu }\end{array}$ \\
\hline Agrobio (5\%) & $2,4 \mathrm{Bb}$ & $1,7 \mathrm{Ba}$ & 3,3 $\mathrm{Aa}$ & $1,20 \mathrm{Bb}$ & $1,86 \mathrm{Ab}$ & $1,73 \mathrm{Aa}$ \\
\hline $\begin{array}{l}\text { Estreptomicina+ } \\
\text { oxite tretraciclina } \\
\left(0,8 \mathrm{~g} \cdot \mathrm{L}^{-1}\right)\end{array}$ & $3,4 \mathrm{Aa}$ & 2,8 Aa & $3,2 \mathrm{Aa}$ & 1,39 Bb & $1,58 \mathrm{Bb}$ & $2,49 \mathrm{Aa}$ \\
\hline $\begin{array}{l}\text { Oxicloreto de } \\
\text { cobre }\left(2,4 \mathrm{~g} \cdot \mathrm{L}^{-1}\right)\end{array}$ & $1,3 \mathrm{Bc}$ & $1,5 \mathrm{Ba}$ & $2,5 \mathrm{Aa}$ & $8,05 \mathrm{Aa}$ & $4,02 \mathrm{Ba}$ & $2,23 \mathrm{Ca}$ \\
\hline Água & $3,3 \mathrm{Aa}$ & $2,9 \mathrm{Aa}$ & 3,0 Aa & $0,87 \mathrm{Bb}$ & $2,10 \mathrm{Ab}$ & $1,76 \mathrm{Aa}$ \\
\hline $\mathrm{CV} \%$ & \multicolumn{3}{|c|}{17,87} & \multicolumn{3}{|c|}{26,48} \\
\hline
\end{tabular}

*Médias seguidas pela mesma letra, maiúscula na linha e minúscula na coluna, não diferem significativamente pelo teste de Tukey a $5 \%$.

des também não diferiu estatisticamente, tendo oscilado entre 5,51 e 5,90 , se enquadrando dentro da faixa de frutos não ácidos estabelecida por Gould (1974). Apesar de não terem sido observadas diferenças quanto aos teores de sólidos solúveis dos frutos maduros das três cultivares testadas ou efeito dos produtos pulverizados sobre esta mesma variável, observaram-se efeitos destes tratamentos sobre a porcentagem de ATT, expressa pelo teor de ácido cítrico, e sobre o $\mathrm{pH}$ dos frutos. Os frutos colhidos nas parcelas pulverizadas com oxicloreto de cobre apresentaram significativamente maiores teores de ácido cítrico em relação a todos os demais tratamentos e menores valores de $\mathrm{pH}$, apesar de não terem diferido em relação àqueles colhidos nas parcelas pulverizadas com o Agrobio (Tabela 2). Esta diferença afetou a relação SST/ATT dos frutos, resultando em menores valores nos frutos das parcelas pulverizadas com oxicloreto de cobre $(2,96)$ e maiores valores nos frutos das parcelas testemunhas $(6,66)$. Entre as cultivares, observou-se que os frutos de 'Magali R' apresentaram significativamente menores teores de ácido cítrico e, correspondentemente, maior relação SST/ATT, apesar de não terem diferido quanto aos valores de $\mathrm{pH}$ (Tabela 2).

A análise destes resultados, porém, é dificultada pela escassez de informações na literatura sobre a composição e características físico-químicas de frutos de pimentão. Observaram-se, em geral, altos valores de coeficiente de variação, possivelmente pela composição original das amostras, frutos verdes (coloração 1 e 2) e frutos maduros (coloração 3 e 4) e pela própria natureza dos frutos, classificados como não climatéricos ou de transição (Meir et al., 1995).

Embora não existam padrões estabelecidos para frutos de pimentão inferese que os frutos maduros de 'Magali R' foram os que apresentaram melhor balanço entre teor de sólidos solúveis e de ácido cítrico, expresso pela maior relação numérica de SST/ATT. Este balanço caracteriza o sabor do fruto, estando relacionado à presença de diversos constituintes químicos, principalmente os açúcares, expresso em ${ }^{\circ}$ Brix, e ácidos, expresso pela percentagem de ácido cítrico. A principio, quanto maior o teor de açúcares e de ácidos, melhor o sabor do fruto (Grierson \& Kader, 1986).

Observou-se efeito significativo da interação entre cultivar e produto pulverizado sobre o teor de fósforo nos frutos e, efeito significativo apenas de produto sobre o acúmulo de fósforo nos frutos (Tabela 3). A cultivar Cascadura Itaipu apresentou, em geral, maiores teores de fósforo nos frutos, independente do produto pulverizado, enquanto que 'Magda' e Magali R' apresentaram teores significativamente menores quando pulverizadas com Agrobio e, principalmente, oxicloreto de cobre (Tabela 3). Os teores de fósforo observados (1,3 a $3,4 \mathrm{~g} \mathrm{~kg}^{-1}$ ) são inferiores aos encontrados por Furlani et al. (1978) em ensaios com solução nutritiva $\left(4,1 \mathrm{~g} \mathrm{Kg}^{-1}\right)$, mas são semelhantes aos citados em outros trabalhos (Negreiros, 1995; Nannetti, 2001). Os resultados observados no presente trabalho sugerem um possível efeito do cobre sobre a eficiência do uso de fósforo pelas plantas, especialmente pela cultivar Magali R, que apresentou significativamente maior produtividade (Tabela 1) apesar de conteúdo de fósforo $\left(1,94 \mathrm{~kg} \mathrm{ha}^{-1}\right)$ igual estatisticamente ao de 'Magda' $\left(1,00 \mathrm{~kg} \mathrm{ha}^{-1}\right)$ e de Cascadura Itaipu $\left(1,62 \mathrm{~kg} \mathrm{ha}^{-1}\right)$. Ainda, a exportação de fósforo pelos frutos foi significativamente maior nos tratamentos testemunha $\left(2,3 \mathrm{~kg} \mathrm{ha}^{1}\right)$ e sulfato de estreptomicina + oxitetraciclina $(2,6 \mathrm{~kg}$ $\mathrm{ha}^{\mathrm{l}}$ ), tendo sido extraído por ocasião das colheitas duas vezes mais fósforo nestes tratamentos que no tratamento com aplicação de oxicloreto de cobre $(1,2 \mathrm{~kg}$ $\left.\mathrm{ha}^{1}\right)$, sem correspondente aumento de produção. Frutos tratados com agrobio apresentaram $2,1 \mathrm{~kg}^{-1}$ de fósforo. Estes resultados estão de acordo com as observações de Moura et al. (2001) que constataram ampla variação genética em linhagens de pimentão quanto à eficiência nutricional para fósforo e, com os comentários de Voisin (1963) que cita a ocorrência de efeito antagônico entre fósforo e cobre em laranjeira.

Observou-se também, efeito significativo da interação entre cultivares e produtos pulverizados sobre os teores de cobre nos frutos e nenhum efeito dos tratamentos sobre os teores de chumbo. Os frutos de 'Magali R' e, principalmente de 'Magda', colhidos nas parcelas pulverizadas com oxicloreto de cobre apresentaram teores de $\mathrm{Cu}$ significativamente maiores que os dos demais tratamentos (Tabela 3). Pulverizações com Agrobio e com sulfato de estreptomicina + oxitetraciclina não promoveram aumento nos teores de cobre nos frutos de pimentão, tendo apresentado valores igual estatisticamente aos da testemunha água (Tabela 3). A variação no teor de cobre encontrada entre as cultivares, provavelmente, está relacionada com características físicas da superfície dos frutos e precisa ser melhor investigada, tendo em vista a frequiência com que as pulverizações são feitas em períodos favoráveis à ocorrência de epidemias.

Possivelmente, o maior acúmulo de cobre em frutos de 'Magali R', pulverizadas com oxicloreto de cobre, podem 
ter contribuído para a melhor eficiência de utilização de fósforo, pois foram observados coeficientes de correlação (r) significativos e negativos entre teor de cobre e de fósforo $(r=-0,65)$, entre teor de cobre e conteúdo de fósforo $(\mathrm{r}=-0,75)$, entre conteúdo de cobre e teor de fósforo $(r=-0,64)$ e entre conteúdo de cobre e conteúdo de fósforo $(\mathrm{r}=-0,74)$.

Apesar dos teores de cobre no tratamento com oxicloreto de cobre terem sido significativamente superiores aos encontrados nos frutos dos demais tratamentos (Tabela 3), estes ainda se encontram dentro da faixa aceitável para consumo, uma vez que a ingestão diária de cobre recomendada para um adulto (IDR) é de cerca de $3 \mathrm{mg} \mathrm{\textrm {dia } ^ { - 1 }}$ (ANVISA, 1998). Os teores de chumbo encontrados nos frutos dos diferentes tratamentos $\left(0,27\right.$ a $\left.0,34 \mathrm{mg} \mathrm{kg}^{-1}\right)$ também estão dentro da faixa tolerada para consumo.

Pode-se concluir que 'Magali R' é superior às demais cultivares por apresentar maior produtividade, maior massa e diâmetro longitudinal dos frutos e, maior eficiência no aproveitamento do fósforo. Existem diferenças entre as cultivares quanto à taxa de acúmulo de cobre nos frutos, tendo sido quatro vezes maior em frutos de 'Magda' pulverizadas com oxicloreto de cobre que nos demais tratamentos. Os resultados apontam, ainda, para um aumento na eficiência do uso de fósforo com as aplicações de Agrobio e, principalmente, de oxicloreto de cobre, sendo, porém, necessários novos estudos para sua comprovação. Pode-se concluir, ainda, que as aplicações de cobre afetam o sabor dos frutos, principalmente por influenciar em sua acidez total titulável, expressa em maiores teores de ácido cítrico e menores valores de $\mathrm{pH}$.

\section{AGRADECIMENTOS}

Á CAPES pela concessão da bolsa de mestrado ao primeiro e terceiro autores.

\section{REFERÊNCIAS}

AGÊNCIA NACIONAL DE VIGILÂNCIA SANITÁRIA. 2003, 24 de novembro. Portaria $n^{\circ} 33$, de 13 de janeiro de 1998. Disponível em www.anvisa.gov.br

AGUIAR LA. 1997. Identificação de isolados nacionais de Xanthomonas campestris pv. vesicatoria, agente da mancha-bacteriana do pimentão (Capsicum annuиm L.), resistentes ao cobre e perspectivas de seu controle com formulações cúpricas e cuprorgânicas. Seropédica: UFRRJ. 153p (Tese).

BELTRÃO NEM; ALMEIDAO; NOBREGALB. 1988. Estimativas do volume e da área dos frutos do algodoeiro herbáceo por meio de medidas lineares. In: Embrapa. Centro Nacional de Pesquisa do Algodão (Campina Grande, PB). Relatório Técnico Anual do Centro Naciopnal de Pesquisa de Algodão, 1985/1986. Campina Grande: Embrapa-CENPA. p. 143-146.

BUSSEL J; KENIGSBERGER Z. 1975. Packaging green bell peppers in selected permeability films. Journal of Food Science 40: 1300-1303.

CARMO MGF; MACAGNAN D; CARVALHO AO. 2001. Progresso da mancha-bacteriana do pimentão a partir de diferentes níveis iniciais de infecção e do emprego ou não do controle com oxicloreto de cobre. Horticultura Brasileira 19: 342-347.

CHITARRA MIF. 1998. Fisiologia e qualidade de produtos vegetais. In: BORÉM FM (coord.). Armazenamento e processamento de produtos agrícolas. In: CONGRESSO BRASILEIRO DE ENGENHARIA AGRÍCOLA, 27. Anais... Poços de Caldas: p. 1-58.

DE POLLI H. 1998. Manual de Adubação para o Rio de janeiro. Seropédica: UFRRJ. 179p.

DELEITO CSR; CARMO MGF; FERNANDES MCA; ABBOUD ACS. 2005. Ação do biofertilizante Agrobio sobre a mancha-bacteriana e desenvolvimento de mudas de pimentão. Horticultura Brasileira 23: 117-122.

FERNANDES MCA. 2000. O biofertilizante AGROBIO. Informativo do Centro Nacional de Pesquisa de Agrobiologia. Seropédica: EMBRAPA-CNPAB; ano 4, n. 13, Setembro.

FILGUEIRA FAR. 2003. Novo manual de olericultura: agrotecnologia moderna na produção e comercialização de hortaliças. Viçosa: UFV. 402p.

FURLANI AMC; FURLANI OC; HIROCE JR; GALLO JR. 1978. Composição mineral de diversas hortaliças. Bragantia 37: 33-44.

GOULD WA. 1974. Tomato production, processing and quality evaluation. Westport: The AVI. $445 \mathrm{p}$.

GRIERSON D; KADER AA. 1986. Fruit ripening and quality. In: ATHERTON JG; RUDICH J. (eds). The tomato crop: a scientific basis for improvement. London: Chapman Hall. p. 241-280.
GUSMÁN M; ROMERO L. 1988. Iron index of horticultural crops. I. Capsicum anпиит L. cv. Lamnyo. Journal of Plant Nutrition 11: 983994.

INSTITUTO ADOLFO LUTZ. 1976. Método químicos e físicos para análises de alimentos. 2.ed. São Paulo: Instituto Adolfo Lutz, 371p.

McMANUS PS; STOCKWELL VO; SUNDIN GW; JONES AL. 2002. Antibiotic use in plant agriculture. Annual Review of Phytopathology 40: 443-465.

MEIR S; ROSENBERGER I; AHARON Z; GRINBERG S; FALLIK E. 1995. Improvement of the postharvest keeping quality and colour development of bell pepper (cv. "Maor") by packaging with polyethylene bags at a reduced temperature. Postharvest Biology and Technology 5: 303-309.

MOURA WM; LIMA PC; CASALI VWD; PEREIRA PR. 2001. Eficiência nutricional para fósforo em linhagens de pimentão. Horticultura Brasileira 19: 174-180.

NANNETTI DC. 2001. Nitrogênio e potássio aplicados via fertirrigação na produção, nutrição e pós-colheita do pimentão. Lavras: UFLA. 162p (Tese doutorado).

NEGREIROS MZ. 1995. Crescimento, partição de matéria seca, produção e acúmulo de macronutrientes em plantas de pimentão (Capsicum annuum L.) em cultivo podado e com cobertura morta. Viçosa: UFV. 187p. (Tese doutorado).

PEDROSO MFM; LIMA IV. 2001. Ecotoxicologia do cobre e seus compostos. Série Cadernos de Referência Ambiental 2: 128.

RIBEIRO JÚNIOR JI. 2001 Análises estatísticas no SAEG. Viçosa: UFV. 301p.

RIBEIRO GL; LOPES CJ; FILHO MS; RAMALHO SS. 2000. Adubação orgânica na produção de pimentão. Informe Agropecuário 18: 134-137.

SANTOS FS; SOBRINHO NMBA; MAZUR N. 2002. Influência de diferentes manejos agrícolas na distribuição de metais pesados no solo e em plantas de tomate. Revista Brasileira de Ciências do Solo 26: 535-543.

SINGH K; SRIVASTAVA B K. 1988. Effect of various levels of nitrogen and phosphorus on growth and yield of chilli (Capsicum annиum L.). Indian Journal of Horticulture 45: 319324.

TEDESCO MJ; GIANELLO C; BOHNEN H; VOLKWEISS SJ. 1995. Análise de solo, plantas e outros materiais. Porto Alegre: UFRGS. $174 \mathrm{p}$.

TRATCH R; BETTIOL W. 1997. Efeito de biofertilizantes sobre o crescimento micelial e a germinação de esporos de alguns fungos fitopatogênicos. Pesquisa Agropecuária Brasileira 32: 1131-1139.

VOISIN A. 1963. Adubos: novas leis científicas de sua aplicação. São Paulo: Editora Mestre Jou. 130p. 